\title{
In Vivo siRNA Delivery and Rebound of Renal LRP2 in Mice
}

\author{
Michael T. Eadon, Ying-Hua Cheng, Takashi Hato, Eric A. Benson, \\ Joseph Ipe, Kimberly S. Collins, Thomas De Luca, Tarek M. El-Achkar, \\ Robert L. Bacallao, Todd C. Skaar, and Pierre C. Dagher
}

Department of Medicine, Indiana University School of Medicine, Indianapolis, IN 46202, USA

Correspondence should be addressed to Michael T. Eadon; meadon@iupui.edu

Received 11 August 2017; Revised 26 October 2017; Accepted 20 November 2017; Published 20 December 2017

Academic Editor: Ambikanandan Misra

Copyright (C) 2017 Michael T. Eadon et al. This is an open access article distributed under the Creative Commons Attribution License, which permits unrestricted use, distribution, and reproduction in any medium, provided the original work is properly cited.

\begin{abstract}
siRNA stabilized for in vivo applications is filtered and reabsorbed in the renal proximal tubule (PT), reducing mRNA expression transiently. Prior siRNA efforts have successfully prevented upregulation of mRNA in response to injury. We proposed reducing constitutive gene and protein expression of $L R P 2$ (megalin) in order to understand its molecular regulation in mice. Using siRNA targeting mouse LRP2 (siLRP2), reduction of LRP2 mRNA expression was compared to scrambled siRNA (siSCR) in mouse PT cells. Mice received siLRP2 administration optimized for dose, administration site, carrier solution, administration frequency, and administration duration. Kidney cortex was collected upon sacrifice. Renal gene and protein expression were compared by qRT-PCR, immunoblot, and immunohistochemistry (IHC). Compared to siSCR, siLRP2 reduced mRNA expression in PT cells to $16.6 \% \pm 0.6 \%$. In mouse kidney cortex, siLRP2 reduced mRNA expression to $74.8 \pm 6.3 \% 3 \mathrm{~h}$ and $70.1 \pm 6.3 \% 6 \mathrm{~h}$ after administration. mRNA expression rebounded at $12 \mathrm{~h}(160.6 \pm 11.2 \%)$. No megalin renal protein expression reduction was observed by immunoblot or IHC, even after serial twice daily dosing for 3.5 days. Megalin is a constitutively expressed protein. Although LRP2 renal mRNA expression reduction was achieved, siRNA remains a costly and inefficient intervention to reduce in vivo megalin protein expression.
\end{abstract}

\section{Introduction}

RNA interference (RNAi) is an attractive approach to transiently cleave mRNA transcripts and ultimately reduce protein expression $[1,2]$. For a variety of therapeutic indications, synthetic small interfering RNAs (siRNAs) have been modified to effectively mediate in vivo gene and resultant protein expression regulation [3-8]. In the kidney, siRNA stabilized with $2^{\prime} \mathrm{O}$-methylation is filtered and reabsorbed in the renal proximal tubule (PT) following IV administration, reducing relative mRNA expression temporarily in the PT [9]. siRNA directed to candidate genes, including p53, has prevented multiple forms of acute kidney injury (AKI) and renal fibrosis in animal models [10-14].

Investigators have succeeded in reducing relative mRNA expression and mitigating disease phenotypes through either high-dose siRNA administration without a carrier molecule or using lower doses bound to nanoparticles [15-18]. Regardless, a common theme is the prevention of candidate gene upregulation in response to injury or disease. Many of these studies reveal extended reductions in transcript expression; however, these reductions are relative to a scrambled control condition in the setting of gene upregulation. In contrast, we proposed reducing gene and protein expression of a constitutively expressed receptor, $L R P 2$ (megalin), in order to better understand the molecular regulation of this protein.

Megalin, encoded by $L R P 2$, is a $600 \mathrm{kDa}$ cell surface endocytic receptor found in the apical membrane of renal proximal tubule epithelial cells [19]. Megalin complexes with cubilin and is important in the reabsorption of trace elements, thyroglobulin, and carrier-bound vitamins [20]. Megalin has been implicated in the uptake of several nephrotoxins, including folate, cadmium, gentamicin, and colistin [21-24]. Receptor activated protein (RAP) and cilastatin have been shown to block the reabsorption of these toxins through megalin-mediated endocytosis [21, 22]. RNAi of LRP2 may hold similar therapeutic potential.

Although megalin has an extended half-life [25], other investigators have succeeded in providing serial daily or twice 
weekly administration of siRNA to reduce renal expression of other genes and proteins [11-13]. We hypothesized that serial administration could similarly reduce megalin expression. After significant optimization, successful knockdown of LRP2 mRNA expression was achieved in mice. However, a prominent rebound effect in $L R P 2$ mRNA transcript expression was observed. The rebound effect, coupled with the extended half-life of the protein, precluded attaining a reduction in protein expression. We present the data here in order to facilitate optimization for other investigators. Target selection is important. We conclude that the prevention of upregulated expression holds greater feasibility than knockdown of a constitutively expressed protein.

\section{Methods}

2.1. Cell Culture. Mouse S1 proximal tubular (mS1PT) cells were previously isolated from a mouse carrying the SV40 large T-antigen transgene $[26,27]$. BUMPT mouse proximal tubular cells were a gift from the Patrick Cunningham Laboratory. Cells were maintained in DMEM/F12 (S1) medium (Corning Cellgro, Corning, NY, USA) supplemented with $10 \%$ fetal bovine serum (HyClone) and $1 \%$ penicillinstreptomycin (MP Biomedicals, Santa Ana, CA, USA). Cells were split when they reached $70-80 \%$ confluence and diluted to $20-30 \%$ confluency thrice weekly. Mouse proximal tubular cells were maintained at $37^{\circ} \mathrm{C}$ in $95 \%$ humidified atmosphere with $5 \% \mathrm{CO}_{2}$.

2.2. siRNA Nucleofection. mS1PT cells were diluted to 500,000 cells $/ \mathrm{ml}$ one day prior to nucleofection. Cells were nucleofected using the SF Cell Line Amaxa X-system Nucleofector Kit (Lonza, Inc., Basel, Switzerland) and the CA-137 program on Lonza's 4D-Nucleofector Amaxa X-system. Cells were then centrifuged at $90 \mathrm{~g}$ for $10 \mathrm{~min}$ at room temperature and resuspended at a concentration of $1,000,000$ cells $/ 20 \mu \mathrm{l}$ in SF/supplement solution (SF Kit, Lonza Catalog V4SC2096) and $2000 \mathrm{nM}$ final total siRNA concentration for one of seven conditions. The seven conditions included (1) All Stars Negative Control siRNA (Qiagen, Inc., Valencia, CA, USA) at $2000 \mathrm{nM}$ concentration, (2) a pool of four Dharmacon siLRP 2 constructs at a $500 \mathrm{nM}$ concentration for each siRNA molecule, (3) through (6) each of the four individual Dharmacon siLRP2 constructs at a $2000 \mathrm{nM}$ concentration (GE Dharmacon, Lafayette, CO, USA), or (7) an Ambion in vivo siLRP2 molecule at a $2000 \mathrm{nM}$ concentration (Thermo Fisher Scientific, Waltham, MA, USA). Cells were allowed to rest for $10 \mathrm{~min}$ prior to the addition of prewarmed $\left(37^{\circ} \mathrm{C}\right.$ water bath) S1 media and then for another $5 \mathrm{~min}$ in the warm S1 media. Cells were then plated for mRNA harvest or drug treatment. mS1PT cells were harvested 24, 48, 72, 96, 120, and $144 \mathrm{~h}$ after nucleofection for mRNA expression measurements.

2.3. Animals and siRNA Administration. Sixty-nine male C57BL/6NHsd and eight Swiss Webster mice were obtained and studied at 6-8 wk of age (Envigo Laboratories, Indianapolis, IN, USA). All experimentation was approved by the Institutional Animal Care and Use Committee (IACUC) at Indiana University School of Medicine.
Optimization of administration site and carrier solution was assessed. All animals received injections of Ambion in vivo siLRP2, molecular grade phosphate-buffered saline (PBS) vehicle, Invivofectamine (IVFM) vehicle (IVF3005, Thermo Scientific, Waltham, MA, USA), or scrambled siRNA (On-Target Plus Control Nontargeting siRNA \#2 D-00181002-20, Thermo Scientific). Administrations were provided through tail vein injections, direct intrajugular (IJ) vein injections, or IJ intravenous catheter infusions. All animal studies were conducted with in vivo siLRP2 and animals received doses of either $7.5 \mathrm{mcg} / \mathrm{gm}$ or $15 \mathrm{mcg} / \mathrm{gm}$ body weight. These doses corresponded to concentrations of $0.75 \mathrm{mcg} / \mu \mathrm{l}$ or $1.5 \mathrm{mcg} / \mu \mathrm{l}$ siLRP2 prepared in either Invivofectamine or PBS according to the manufacturer's instructions. The initial starting dose of $7.5 \mathrm{mcg} / \mathrm{gm}$ body weight was selected to match Ambion's recommended starting dose of in vivo siRNA. This dose was also compared to previously published studies of siRNA delivery in mice which were effective at achieving gene knockdown [10-14]. C57BL/6 mice (20 g weight) were used for all experiments except the 3.5-day serial siRNA administration, in which the larger Swiss Webster mice (35 g weight) were employed to tolerate larger daily volumes of siRNA or vehicle. Mice were euthanized by exsanguination and cervical dislocation at appropriate time points with collection of blood, kidney tissue, liver tissue, and lung tissue. Three mice died prior to experimental endpoints due to surgical mortality or because they required euthanasia for catheterrelated malfunctions.

2.4. Jugular Venous Catheter Placement. Mice were anesthetized with isoflurane. Hair was removed from the surgical site by clippers followed by the hair remover lotion Nair (CVS Pharmacy, Woonsocket, RI, USA) and then disinfected three times with alternating scrubs of iodine and $70 \%$ alcohol. A 5-8 mm longitudinal incision was made on the ventral surface of the neck, $5 \mathrm{~mm}$ right of the midline. The right jugular vein was exposed and then catheterized by a polyurethane mouse jugular vein catheter (ID, $0.43 \mathrm{~mm}$; OD, $0.69 \mathrm{~mm}$ with a collar of $0.9 \mathrm{~mm}$ OD, from Instech Laboratories, Inc., Plymouth Meeting, PA, USA) preinfused with PBS. The catheter was secured in place by suturing around the cannulated jugular vein and surrounding tissue, and its free end was connected to a 25 ga PinPort (Instech Laboratories). The catheter and PinPort were tunneled subcutaneously around the neck and exteriorized from the dorsal side. The exposed PinPort was secured on the skin with two sutures and $3 \mathrm{M}$ Vetbond surgical glue (Revival Animal Health, Orange City, IA, USA). After surgery, the catheter was flushed with PBS twice daily.

2.5. Tissue Collection, Fixation, and Freezing. Kidneys were fixed or frozen for routine histologic analysis, immunohistochemistry, immunoblot, and real-time PCR. Kidneys were obtained at sacrifice, cut transversely, and fixed in formalin or the cortex was isolated and flash-frozen in Eppendorf tubes with liquid nitrogen. The frozen kidney cortex was stored at $-80^{\circ} \mathrm{C}$ for subsequent quantitative realtime polymerase chain reaction (qRT-PCR) and immunoblot analysis. For formalin-fixed tissue, specimens were stored in 
TABle 1: Primer sequences.

\begin{tabular}{lc}
\hline Molecule & Sequence $\left(5^{\prime}-3^{\prime}\right)$ \\
\hline LRP2 F primer & CCT TGC CAA ACC CTC TGA AAA T \\
LRP2 R primer & CAC AAG GTT TGC GGT GTC TTT A \\
18S F primer & GTT GGT GGA GCG ATT TGT CT \\
18S R primer & GAA CGC CAC TTG TCC CTC TAT \\
\hline
\end{tabular}

$4 \%$ phosphate-buffered formalin for 6 hours prior to transfer to $70 \%$ ethanol. Specimens were then brought to the core pathology lab for embedding, cutting, and immunohistochemistry or periodic acid-Schiff (PAS) staining.

2.6. Quantitative Real-Time PCR. qRT-PCR was performed to measure the levels of expression of $L R P 2$ in $\mathrm{mS1PT}$ cells or in mouse kidney cortex. For cell experiments, a total of 1 million cells were pelleted $24,48,72,96,120$, and $144 \mathrm{~h}$ after nucleofection, washed in ice-cold PBS, and centrifuged to remove PBS. All pellets were flash-frozen and stored at $-80^{\circ} \mathrm{C}$ until RNA isolation. Total RNA was extracted using the miRNeasy Plus Mini Kit (Qiagen) following the manufacturer's protocol. RNA was isolated and purified from frozen mouse kidney tissue as previously described [28].

RNA quality assessment and quantification were conducted using the optical spectrometry 260/280 and $260 / 230 \mathrm{~nm}$ ratios. Subsequently, mRNA was reverse transcribed to cDNA using the Bio-Rad iScript Reverse Transcription Kit (Bio-Rad, Hercules, CA, USA). The final concentration of cDNA was $25 \mathrm{ng} / \mu \mathrm{l}$. qRT-PCR was performed for $L R P 2$ and $18 S$ (used as an endogenous control) with custom made primers (Life Technologies, Carlsbad, CA, USA) and iTaq Universal SYBR Green (Bio-Rad) on the Applied Biosystems ViiA 7 RT-PCR system. Primer sequences are provided in Table 1 . The entire reaction was performed in $20 \mu \mathrm{l}$ volume, which consisted of $10 \mu \mathrm{l}$ SYBR green, $4 \mu \mathrm{l} \mathrm{cDNA}, 0.4 \mu \mathrm{l}$ of each primer ( $10 \mu \mathrm{M}$ stock), and $5.2 \mu \mathrm{l}$ of water. The thermocycler parameters were $95^{\circ} \mathrm{C}$ for $30 \mathrm{~s}, 40$ cycles of $95^{\circ} \mathrm{C}$ for $15 \mathrm{~s}$, and then a lower temperature for $30 \mathrm{~s}\left(18 \mathrm{~S}: 60^{\circ} \mathrm{C}, L R P 2: 58^{\circ} \mathrm{C}\right)$, with ramping speeds of $1.6-1.98 \mathrm{C} / \mathrm{s}$ and a melt curve. The CT threshold and baseline for each experiment were set automatically by the ViiA 7 software.

The delta-delta $(\Delta \Delta \mathrm{CT})$ method was used to obtain the relative expression of each gene. Each sample's expression of $L R P 2$ was first subtracted from its $18 S$ expression to determine its $\Delta \mathrm{CT}$. The $\Delta \mathrm{CT}_{\text {scramble }}$ for cell experiments or the $\Delta \mathrm{CT}_{\text {control }}$ for live animals was then subtracted from the $\Delta \mathrm{CT}_{\text {siRNA }}$ to determine the $\Delta \Delta \mathrm{CT}$. Fold change of the siRNA knockdown as compared to the control was determined by the formula fold change $=2^{\Delta \Delta C T}$. mRNA expression for each condition is given as a percentage of expression relative to the control condition.

2.7. Immunoblot. To assess megalin protein expression, proteins were extracted from either an mS1PT cell pellet or a portion of frozen kidney cortex and stored at $-80^{\circ} \mathrm{C}$. Pierce Radioimmunoprecipitation assay buffer (Pierce Biotechnology, Rockford, IL, USA) with $1 \%$ Pierce protease inhibitor
(Pierce Biotechnology, Rockford, IL, USA) was used to prepare protein samples. An immunoblot was performed with $20 \mu \mathrm{g}$ of protein per lane $(n=4$ per group) on a NuPAGE ${ }^{\circledR} 3-8 \%$ Tris-Acetate Gel (1.0-mm, 10 wells, Invitrogen, Life Technologies, Carlsbad, CA, USA). A goat polyclonal antibody to megalin $(1: 500$, SC-16478, Santa Cruz Biotechnology, Inc., Dallas, TX, USA) was incubated for 2 hours at room temperature and a secondary donkey anti-goat antibody (1:5000, SC-2020, Santa Cruz Biotechnology, Inc.) for 45 minutes. As previously described [29], relative megalin expression was calculated as compared to $\beta$-actin control (1:250, SC-47778, Santa Cruz Biotechnology, Inc.) with ImageJ software (v1.44p, NIH) [30].

2.8. Immunohistochemistry. Kidney sections were fixed in $10 \%$ neutral buffered formalin (EMD Chemicals Inc., Gibbstown, NJ, USA) for 6 hours at room temperature and then transferred to $70 \%$ ethanol. Specimens were paraffinembedded, sectioned, and stained using the antibody to megalin (1:100, SC-16478, Santa Cruz Biotechnology, Inc.), followed by a HRP-conjugated secondary antibody donkey anti-goat (SC-2020, Santa Cruz Biotechnology, Inc.) after deparaffinization and heat antigen retrieval in citrate buffer. Tubular staining intensity was scored by pixel density quantitatively using Image) software (minimum $n=3$ mice, with 10 fields per mouse) and semiquantitatively in terms of intensity on a scale of $0-3(0=$ none, $1=$ weakly positive, $2=$ positive, and $3=$ strongly positive).

2.9. Statistics. For cell experiments, statistical significance was assessed based on a Student's $t$-test for two comparisons or ANOVA for 3 or more groups. Between control and siLRP2 treated animals, a Student's $t$-test was used to compare expression.

\section{Results}

3.1. siRNA Targeted to LRP2 in S1 Renal Tubular Epithelial Cells Reduces Relative mRNA Expression. In order to ultimately achieve in vivo knockdown of $L R P 2$, the gene encoding megalin, we began with a series of in vitro experiments to optimize the siRNA sequence and timing of administration. Baseline LRP2 mRNA expression was screened in two mouse proximal tubular cell lines, mS1PT and BUMPT, by qRT-PCR. Baseline raw CT values in mS1PT cells ranged from 22.5 to 23.5, while baseline CT values in BUMPT cells ranged from 28 to 30 . Due to their significantly higher mRNA expression of LRP2, mS1PT cells were selected for downstream experimentation.

Four siRNA sequences targeting $L R P 2$ were examined individually and as a pool for their efficacy in reducing $L R P 2$ mRNA expression in mS1PT cells (Figure 1(a)). All sequences significantly reduced mRNA expression as compared to a scrambled control siRNA (siSCR). siRNA sequence 4 led to the most profound reduction in mRNA expression, down to $16.6 \pm 1.0 \%$ as compared to the scrambled control $(p=$ $\left.4.6 \times 10^{-10}\right)$.

The best performing standard siLRP2 (sequence number 4) was then compared to both the siSCR and a modified 


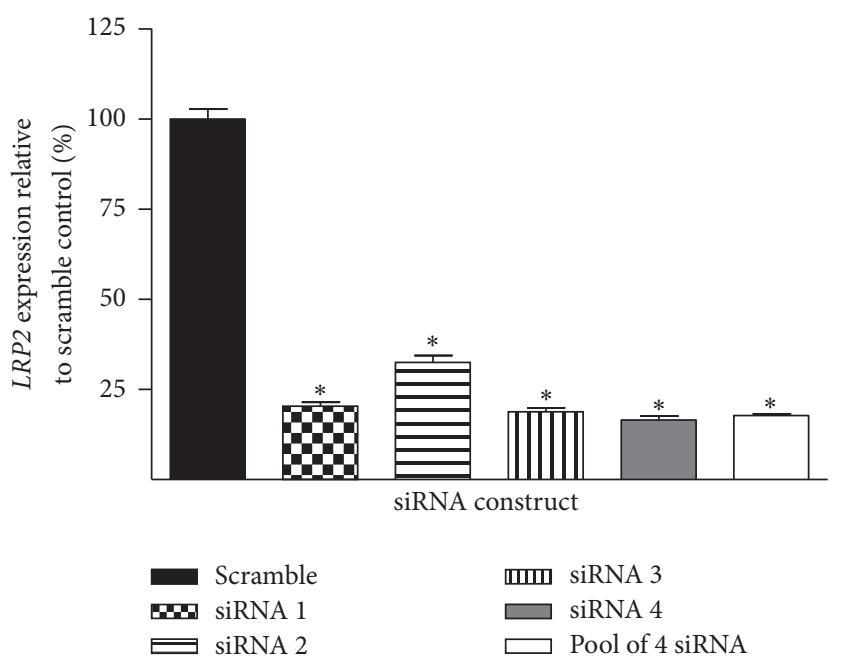

(a)

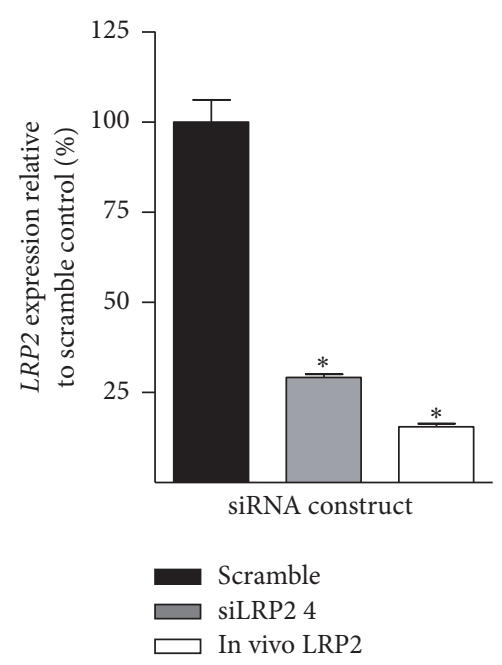

(b)

FIGURE 1: In vitro siLRP2 knockdown leads to reduction of mRNA expression in renal S1 proximal tubule cells. (a) All four commercially available siRNA molecules targeting $L R P 2$ reduced mRNA expression, individually and as a pool. siRNA \# 4 led to the strongest knockdown, reducing mRNA expression to $16.6 \pm 1.0 \%\left(p=4.6 \times 10^{-10}\right)$. (b) In vivo siLRP2 led to significant knockdown in $\mathrm{mS1PT}$ cells as well $15.6 \pm$ $0.9 \%\left(p=7.2 \times 10^{-8}\right) .{ }^{*} p<0.05$ as compared to the scrambled control.

Ambion in vivo siLRP2. Although the Ambion sequence modifications are proprietary, many siRNA constructs created for in vivo application utilize $2^{\prime} \mathrm{O}$-methylation modifications to stabilize the siRNA against degradation [31]. We examined whether these modifications might impact the efficacy of in vivo siLRP2. Expression was measured by qRTPCR (Figure 1(b)) in proximal tubular cells. Both the standard and in vivo siLRP2 molecules significantly reduced mRNA expression as compared to siSCR treatment. In vivo siLRP2 outperformed si $L R P 2$ sequence 4 in cell culture, eliciting a reduction of $L R P 2$ mRNA expression to $15.6 \pm 0.9 \%$ of siSCR treated expression $\left(p=7.2 \times 10^{-8}\right)$.

3.2. In Vivo siLRP2 Reduces LRP2 mRNA Expression for Days in Renal Tubular Epithelial Cells. We then sought to determine the duration of expression reduction in renal tubular epithelial cells. mS1PT cells treated with in vivo siLRP2 or siSCR were harvested 24, 48, 72, 96, 120, and 144 hours following nucleofection and expression was measured by RTPCR. LRP2 mRNA expression remained suppressed for 96 hours following nucleofection (Figure 2(a)). Nadir expression was found $48 \mathrm{~h}$ after nucleofection at $11.5 \pm 1.0 \%$ of scrambled control expression $\left(p=2.0 \times 10^{-6}\right) . L R P 2$ expression was increased in siLRP2 treated cells as compared to siSCR treated cells at 144 hours after nucleofection $(163.3 \pm 2.9 \%, p=1.3 \times$ $10^{-7}$ ).

To confirm that knockdown of protein accompanied mRNA expression reductions in proximal tubular cells, protein expression of megalin was measured in untreated $\mathrm{mS1PT}$ cells and in cells 24 and 48 hours after nucleofection by immunoblot (Figures 2(b)-2(c)). Abundant megalin expression was found in siSCR mS1PT cells, but not in those exposed to siLRP2.
3.3. siLRP2 Reduced Renal mRNA Expression In Vivo. While prolonged LRP2 mRNA suppression was achieved in renal cell culture, the degree of exposure time and concentration of the siRNA in cell culture constructs are unlikely to be achieved in vivo. Prior in vivo studies have revealed that fluorescently tagged siRNA targeting P53 remains in contact with the renal proximal tubule for at least 2 hours. The siRNA is absent from the nephron at 24 hours, but renal mRNA expression remains reduced for 24 hours [9]. We used the information obtained from the cell culture experiments above, prior published literature, and the siRNA manufacturer's guidelines to conduct animal experimentation. All experimentation was conducted with in vivo siLRP2. In order to assess its efficacy, mice were given a single dose of $7.5 \mathrm{mcg} / \mathrm{gm}$ body weight of in vivo siLRP2 or PBS vehicle by tail vein injection and mRNA expression was measured $24 \mathrm{~h}$ after administration (Figure 3(a)). The dose corresponded to a 3-fold higher amount as compared to historical doses of siRNA delivered to the kidney in PBS [11-13] and corresponds to the manufacturer's highest recommended dose. mRNA expression in mice receiving siLRP2 was not significantly different from control mice; however an unexpected trend toward increased LRP2 expression was observed $24 \mathrm{~h}$ after mice received siLRP2 (expression of $135.7 \pm 15.1 \%$ compared to control, $p=0.084$ ).

We considered that the lack of mRNA expression reduction with siLRP2 may be secondary to (1) restoration of mRNA expression at $24 \mathrm{~h}$, (2) inadequate dose, or (3) inefficacy of the siRNA in mice. We then tested the effect of dose at an earlier time point. Using tail vein injections, mice received a single dose of one of the following: (1) PBS vehicle, (2) $7.5 \mathrm{mcg} / \mathrm{gm}$ in vivo siLRP2, (3) $15 \mathrm{mcg} / \mathrm{gm}$ in vivo siLRP2, or (4) an siRNA negative control. mRNA expression was 


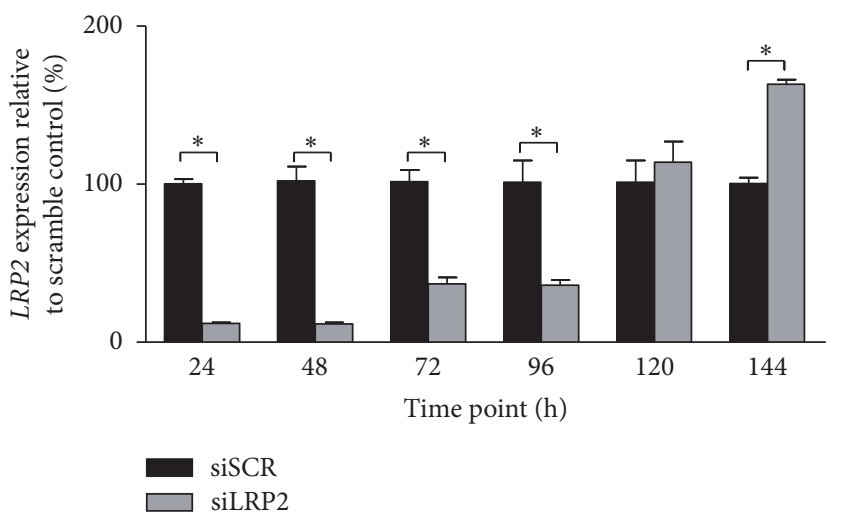

(a)

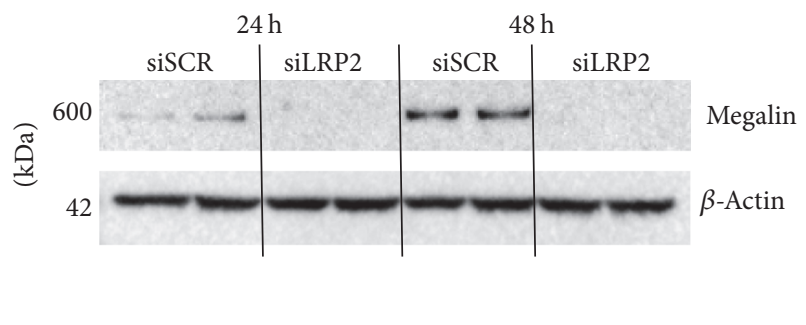

(b)

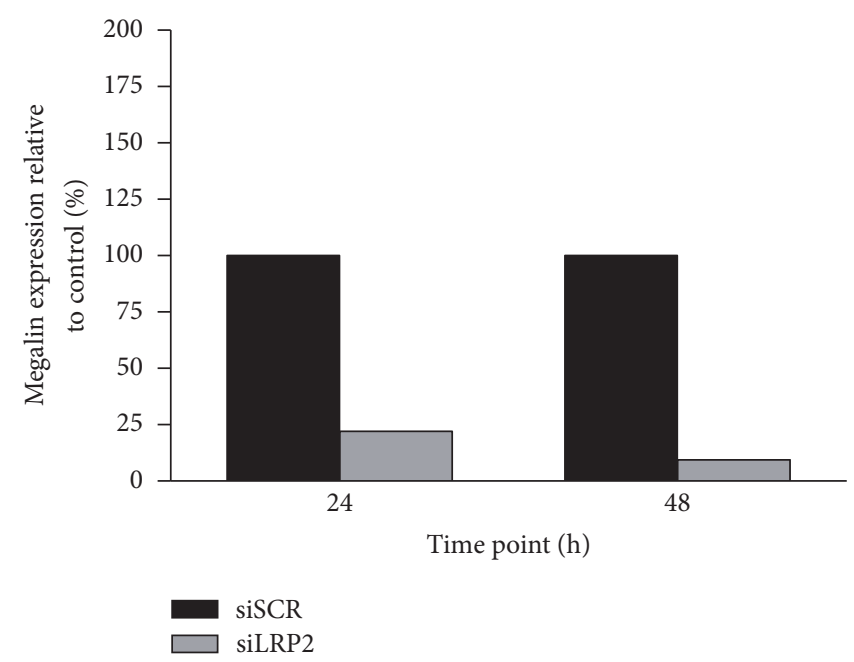

(c)

FIGURE 2: LRP2 mRNA expression in mS1PT cells is reduced. (a) Knockdown persists for at least $96 \mathrm{~h}$ and reaches baseline expression by $120 \mathrm{~h}$ ( $N=3$ cell culture experiments). Expression is increased as compared to scrambled (siSCR) expression at $144 \mathrm{~h}$. (b) Megalin immunoblot reveals decreased protein expression in S1 proximal tubular cells treated with siLRP2. (c) Expression was reduced to $22.4 \% 24 \mathrm{~h}$ after siLRP2 administration and $9.1 \% 48 \mathrm{~h}$ after siLRP2 administration $(N=2$ cell culture experiments). Densitometry was normalized to a beta-actin control. ${ }^{*} p<0.05$ as compared to the siSCR control.

measured $3 \mathrm{~h}$ after administration. At $3 \mathrm{~h}, L R P 2$ expression was not significantly different between mice receiving PBS vehicle and those receiving $7.5 \mathrm{mcg} / \mathrm{gm}$ siLRP2 (Figure 3(b)). However, mice receiving $15 \mathrm{mcg} / \mathrm{gm}$ si $L R P 2$ had $25.2 \%$ lower expression of $L R P 2$ as compared to control mice (expression reduced to $74.8 \pm 6.3 \%, p=0.034$ ). To confirm expression reduction was specific to $S I L R P 2$ administration, a second set of control mice were given an in vivo modified scrambled siRNA (siSCR, nontargeting) as a control. Mice injected with siSCR did not have significant $L R P 2$ expression reduction. A trend toward increased LRP2 expression was observed $(139 \pm 26.9 \%, p=0.082)$ in mice receiving the siSCR control. Due to the trend toward increased LRP2 expression in mice receiving the siSCR, PBS vehicle was used as a control in downstream experimentation in order to be more conservative with comparisons. Analogously, the $15 \mathrm{mcg} / \mathrm{gm}$ siLRP2 dose was used in downstream applications, a dose that is 6-fold higher than what most investigators have used to successfully reduce renal mRNA expression in the past [1113].
We then examined the duration of effect of the in vivo siLRP2 (Figure 3(c)). Mice were given a single dose of siLRP2 at $15 \mathrm{mcg} / \mathrm{gm}$ or PBS vehicle and sacrificed at $6 \mathrm{~h}$ and $12 \mathrm{~h}$ following tail vein administration. At $6 \mathrm{~h}, L R P 2$ expression was reduced to $70.1 \pm 6.3 \%$ compared to control $(p=0.015)$. At $12 \mathrm{~h}, \mathrm{LRP} 2$ expression was significantly higher in mice receiving siLRP2 as compared to control (expression of 160.6 $\pm 11.2 \%$ compared to control, $p=0.002$ ).

\subsection{LRP2 Renal Expression Knockdown Is Not Dependent} upon Administration Site. We considered that siRNA delivered through tail vein injections would enter hepatic circulation first and this might impact efficacy. Thus, we examined the difference in degree of mRNA expression reduction in mice given siLRP2 through tail vein and internal jugular vein injections. Mice received a single dose of siLRP2 or vehicle and were sacrificed $3 \mathrm{~h}$ after administration. Mice receiving internal jugular administration of siLRP2 had lower LRP2 expression $(55.1 \pm 16.0 \%)$ as compared to control mice 

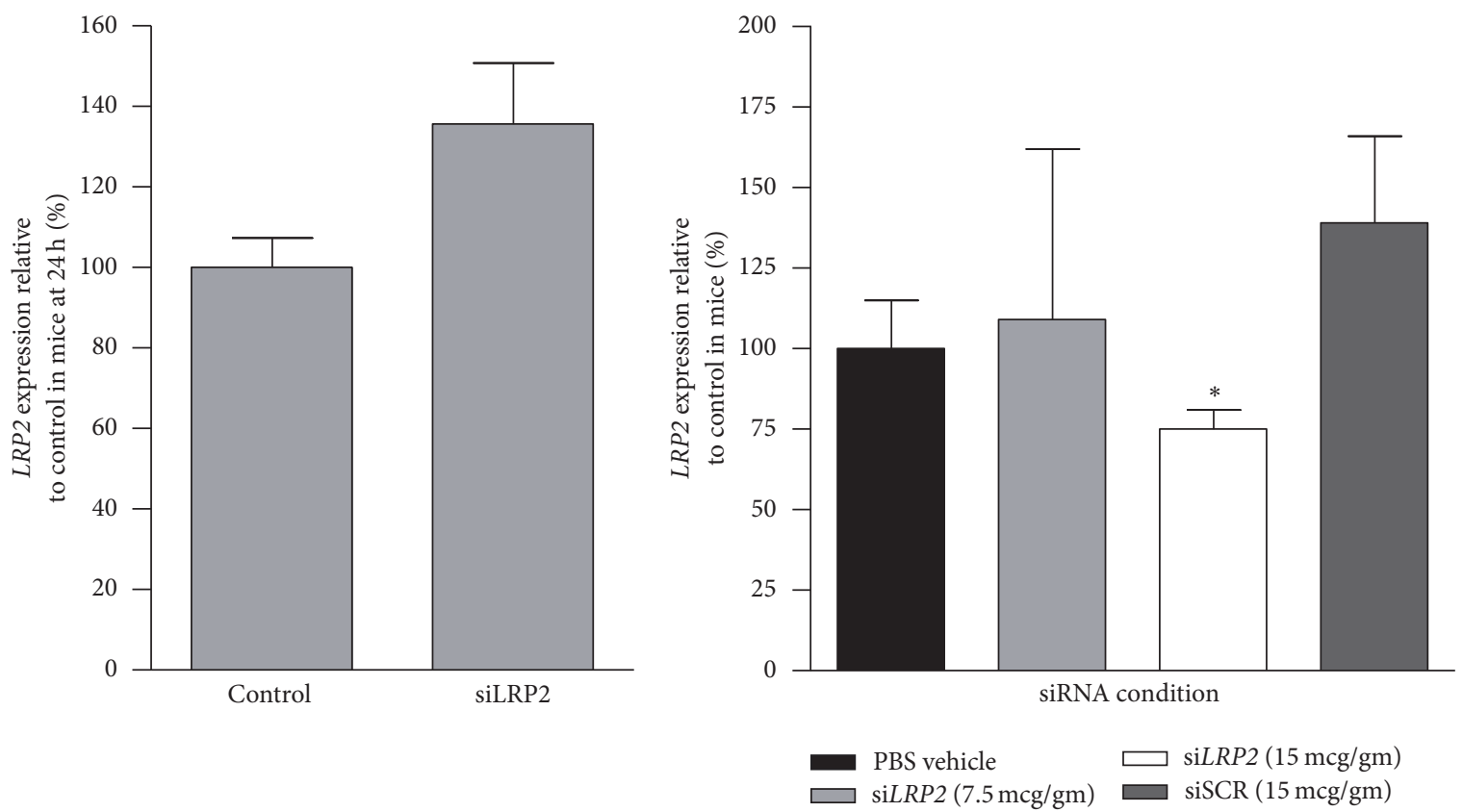

(a)

(b)

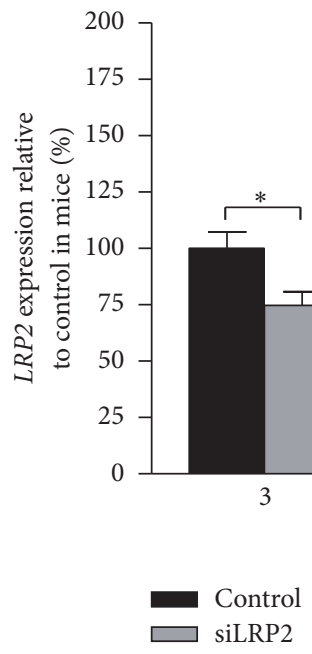

FiguRE 3: siLRP2 reduced renal mRNA expression in vivo. (a) At $24 \mathrm{~h}$ after $7.5 \mathrm{mcg} / \mathrm{gm}$ siLRP2 administration, expression of $L R P 2 \mathrm{was}$ not reduced in mouse kidney $(n=5$ control, $n=4$ siLRP2). (b) At $3 \mathrm{~h}$ after siLRP2 administration, mice receiving $7.5 \mathrm{mcg} / \mathrm{gm}$ did not have $L R P 2$ expression reduction. Mice receiving $15 \mathrm{mcg} / \mathrm{gm}$ had $25.2 \%$ lower $L R P 2$ expression as compared to control $(p=0.034)$. Mice receiving a modified in vivo scrambled siRNA (siSCR) did not have $L R P 2$ expression reduction ( $n=4$ per group). (c) At $6 \mathrm{~h}$ after $15 \mathrm{mcg} / \mathrm{gm} \mathrm{siLRP2}$ administration, mice receiving siLRP2 had lower expression of $L R P 2$ as compared to control mice. At $12 \mathrm{~h}$ after $15 \mathrm{mcg} / \mathrm{gm} \mathrm{siLRP2, \textrm {mice }} \mathrm{had}$ increased expression as compared to control ( $n=5$ control, $n=4$ siLRP2 at 6 and $12 \mathrm{~h}$ ). The $3 \mathrm{~h}$ expression data from Figure $3(\mathrm{~b})$ is pictured for reader ease. All siRNA was administered via tail vein and prepared in PBS vehicle. ${ }^{*} p<0.05$ as compared to the control or PBS vehicle.

$(p=0.019)$. No significant difference in knockdown was appreciated between mice receiving internal jugular injections and those receiving tail vein injections $(p=0.62)$. In mice receiving either tail vein or internal jugular injections of siLRP2, both had significantly lower expression of $L R P 2$ $3 \mathrm{~h}$ after administration as compared to control mice (Figure $4(\mathrm{a}))$.

Internal jugular injections were administered through direct injection via a cutdown procedure or through an implanted internal jugular catheter. We compared administration from an internal jugular vein cut down or through an internal jugular catheter (Figure 4(b)). Neither technique individually reached statistical significance as compared to control mice due to variability in control LRP2 expression. $L R P 2$ expression did not significantly vary between techniques. Mice receiving a direct injection of siRNA into the internal jugular had $38.2 \pm 17.0 \%$ of control expression and mice receiving siRNA through a catheter had $62.7 \pm 9.2 \%$ 


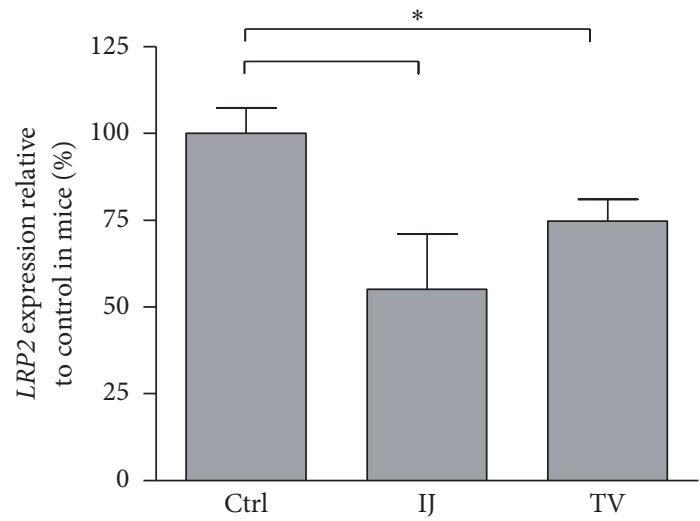

(a)

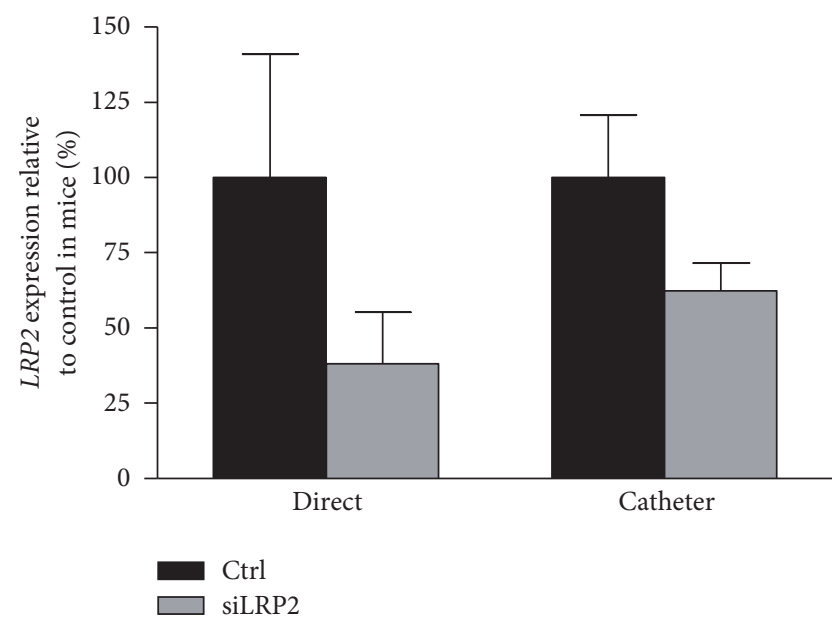

(b)

FIGURE 4: LRP2 renal expression knockdown is not dependent upon administration site. (a) Significant knockdown was appreciated in mice receiving siLRP2 through the internal jugular vein or the tail vein at $3 \mathrm{~h}(n=15$ control, $n=10$ internal jugular (IJ), and $n=4$ tail vein (TV)). Control mice include those receiving vehicle by internal jugular or tail vein injection. (b) For mice receiving siLRP2 through the internal jugular vein, no difference was noted between those receiving direct IJ injections ( $n=3$ control and siLRP2) and those receiving siRNA through an IJ catheter ( $n=7$ control, and siLRP2). ${ }^{*} p<0.05$ as compared to the control (Ctrl).

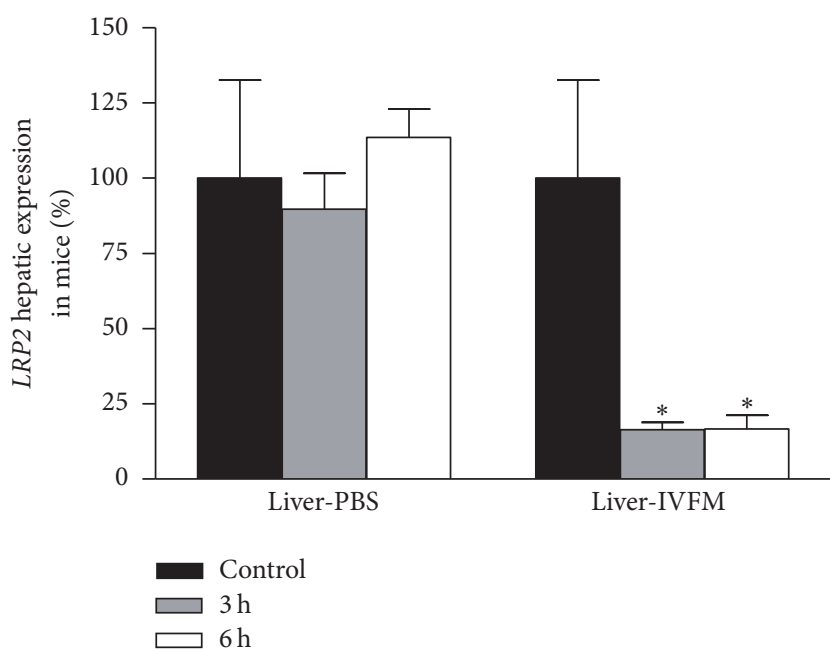

(a)

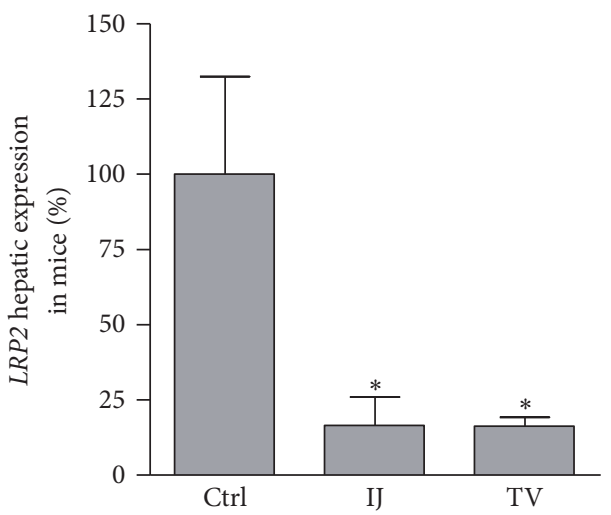

(b)

FIGURE 5: In vivo siLRP2 is effective at reducing $L R P 2$ gene expression in mouse liver. (a) In mouse liver, siLRP2 prepared in the carrier molecule Invivofectamine (IVFM) had lower measured LRP2 expression than control mice or those receiving siLRP2 in PBS ( $n=5$ control, $n=6$ PBS carrier at $3 \mathrm{~h}, n=5$ IVFM carrier at $3 \mathrm{~h}, n=3$ of IVFM, and PBS at $6 \mathrm{~h}$ ). (b) Mice receiving siLRP2 by internal jugular (IJ) or tail vein (TV) injection both achieved reduced LRP2 expression in liver. ${ }^{*} p<0.05$ as compared to the control (Ctrl).

expression of control mice $(p=0.20)$. Thus, the findings in Figure 4(a) were pooled from both internal jugular vein administration procedures to show significant LRP2 knockdown as compared to control mice.

3.5. In Vivo siLRP2 Is Effective at Reducing LRP2 $m R N A$ Expression in Mouse Liver. Although significant mRNA expression knockdown was appreciated in kidney tissue, the degree of knockdown was modest. Ambion's in vivo siRNA is optimized for hepatic expression reduction [32]. In the renal proximal tubule, siRNA dissolved in molecular grade PBS can be reabsorbed via endocytosis after it is filtered through the glomerulus [9]. In contrast, a carrier molecule is often required for hepatic uptake [32]. As a positive control for siRNA efficacy, we examined the degree of LRP2 knockdown in liver tissue $3 \mathrm{~h}$ or $6 \mathrm{~h}$ after a single administration of siLRP2 (Figure 5). siRNA was prepared in either PBS or the carrier molecule, Invivofectamine (IVFM). siLRP2 in PBS carrier did not lead to a reduction in hepatic LRP2 expression as compared to control mice at either $3 \mathrm{~h}$ or $6 \mathrm{~h}(89.7 \pm 12.0 \%$ expression at $3 \mathrm{~h}, p=0.61 ; 113.6 \pm 9.4 \%$ expression at $6 \mathrm{~h}$, $p=0.74)$. In contrast, siLRP2 in IVFM led to a significant 


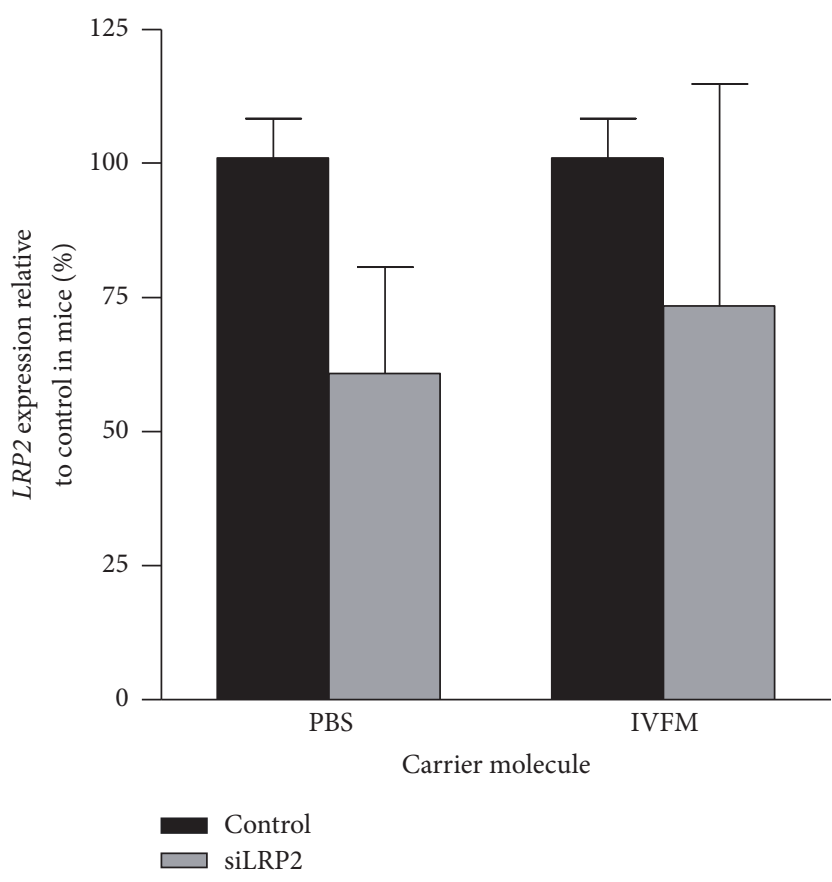

FIGURE 6: Invivofectamine does not improve renal efficacy of siLRP2. As compared to si $L R P 2$ prepared in $\mathrm{PBS}$, preparing si $L R P 2$ in Invivofectamine did not significantly enhance mRNA knockdown ( $n=3$ to 4 per group). Due to the small number of mice used, no statistical difference was observed as compared to control mice.

reduction in expression down to $16.3 \pm 2.6 \%$ as compared to control mouse expression $(p=0.0014)$. The expression reduction was still present $6 \mathrm{~h}$ after administration (reduction to $16.6 \pm 4.6 \%, p=0.011$ ).

We tested whether administration site impacted hepatic $L R P 2$ knockdown at $3 \mathrm{~h}$. Tail vein siLRP2 administration with Invivofectamine reduced expression to $16.3 \pm 3.0 \%(p=$ $0.0016)$ and internal jugular administration reduced expression to $16.5 \pm 9.5 \%(p=0.010)$ of control expression. No difference was observed between the administration sites $(p=0.94)$.

$L R P 2$ expression was also measured in lung tissue and whole blood at $3 \mathrm{~h}$ and $6 \mathrm{~h}$ after siLRP2 administration. However, raw baseline expression CT values ranged from 31 to 35 and were undetectable in some specimens. No conclusions could be drawn regarding knockdown effect in these tissues.

3.6. Invivofectamine Does Not Improve Renal Efficacy of siLRP2. Since siLRP2 prepared in Invivofectamine led to a significant and impressive knockdown in hepatic tissue, we examined whether this carrier molecule could improve reduction of expression in the kidney. Mice were given siLRP2 through the internal jugular vein and sacrificed $3 \mathrm{~h}$ later for expression measurements (Figure 6). siRNA was prepared in either PBS or Invivofectamine. Compared to control mice, siLRP2 in Invivofectamine did not significantly reduce renal expression of $L R P 2$ (expression reduced to $73.5 \pm 41.4 \%$ of control expression, $p=0.72$ ). siLRP2 in PBS reduced mRNA expression at a similar magnitude to previous experiments at
$60.8 \pm 20.0 \%$ expression of control (also nonsignificant with $p=0.11$.

3.7. siLRP2 Did Not Reduce Renal Megalin Protein Expression. We studied the effect of siLRP2 administration on renal cortical protein expression of $600 \mathrm{kDa}$ megalin (Figure 7). Mice were given either vehicle or siLRP2 in PBS through an IJ catheter and sacrificed at $3 \mathrm{~h}$ or $12 \mathrm{~h}$ after administration. $L R P 2$ expression was provided in Figure 3(c). We assessed protein expression by immunohistochemistry. By quantitative analysis with ImageJ, immunohistochemical staining for megalin revealed unchanged cortical expression in proximal tubules ( $p=0.27$ and 0.33 compared to control, resp.). Blinded microscopy supported this finding $(p=0.65$ and 0.14 compared to control, resp.). Immunoblot of cortical kidney protein extract revealed unchanged protein expression at both time points.

We hypothesized that serial administration of siLRP2 may be required to reduce megalin expression. siLRP2 in PBS was administered every 12 hours via an IJ catheter for seven total doses. Mice were sacrificed $3 \mathrm{~h}$ after the seventh dose on day 4 (D4) and compared to mice receiving vehicle alone for 3.5 days. Megalin protein expression remained unchanged as measured by quantitated ImageJ IHC $(p=0.30)$, blinded microscopy $(p=0.22)$, and protein immunoblot with densitometry $(p=0.72)$.

\section{Discussion}

In this investigation, we sought to determine whether in vivo administration of siRNA would succeed in reducing expression of the constitutively expressed gene, LRP2, and its associated protein, megalin. This endeavor builds upon several prior investigations [10-14]. These investigations have succeeded in preventing upregulation of gene expression in response to a stimulus or disease state. In contrast, we were able to reduce baseline mRNA expression, using 6-fold higher doses of siRNA. Reduction of LRP2 expression was attained in mice, but a concomitant protein expression decrease was not observed, even after serial administration. A number of factors may contribute to this finding, including (1) the high proportion of membrane-bound protein as compared to cytoplasmic protein, (2) the modest degree of mRNA reduction, (3) the rapid rebound and increase in mRNA expression following siRNA delivery, and (4) the relatively long half-life of the protein $(4.8 \mathrm{~h})$ [25]. These results support the theoretical use of siRNA to transiently reduce baseline expression of transcripts in the kidney; however, the results also suggest that the practical application of this technique will prove difficult.

Our results build upon the existing body of literature. We have shown that LRP2 rapidly rebounds to a level of mRNA expression which is significantly above baseline expression. This finding has been previously reported in mice for other genes. For example, RNAi targeting the secretory hepatitis B virus surface antigen gene led to an initial gene knockdown followed by an expression rebound [33]. The authors identified upregulation of the meri-1 (mouse enhanced RNAi) and adar-1 (adenosine deaminase acting on 


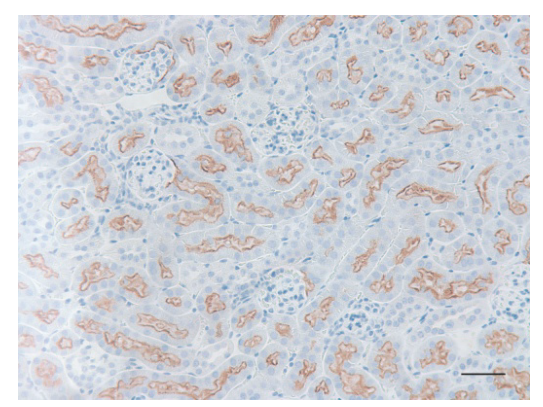

(a)

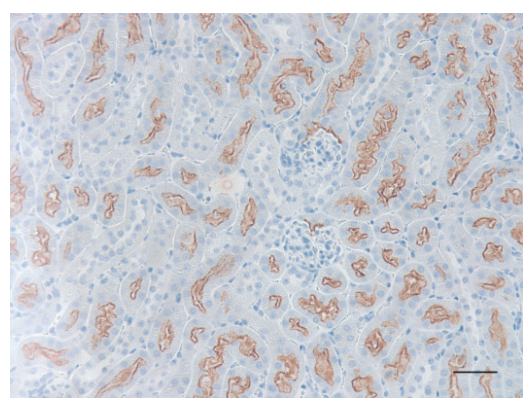

(b)

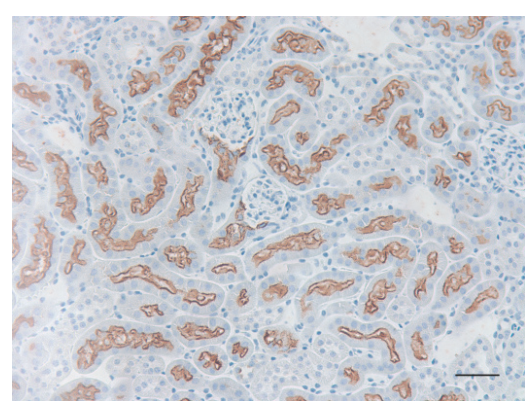

(c)

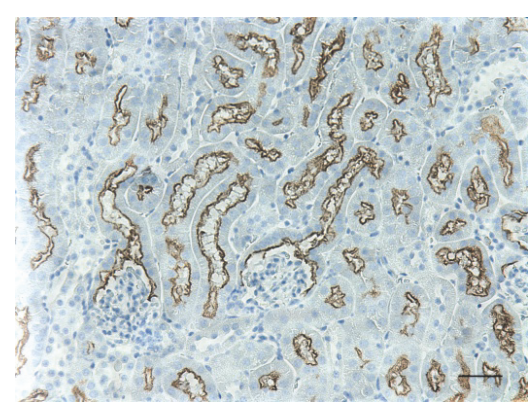

(d)

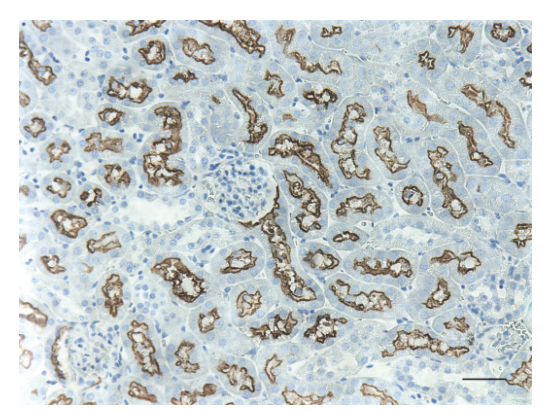

(e)
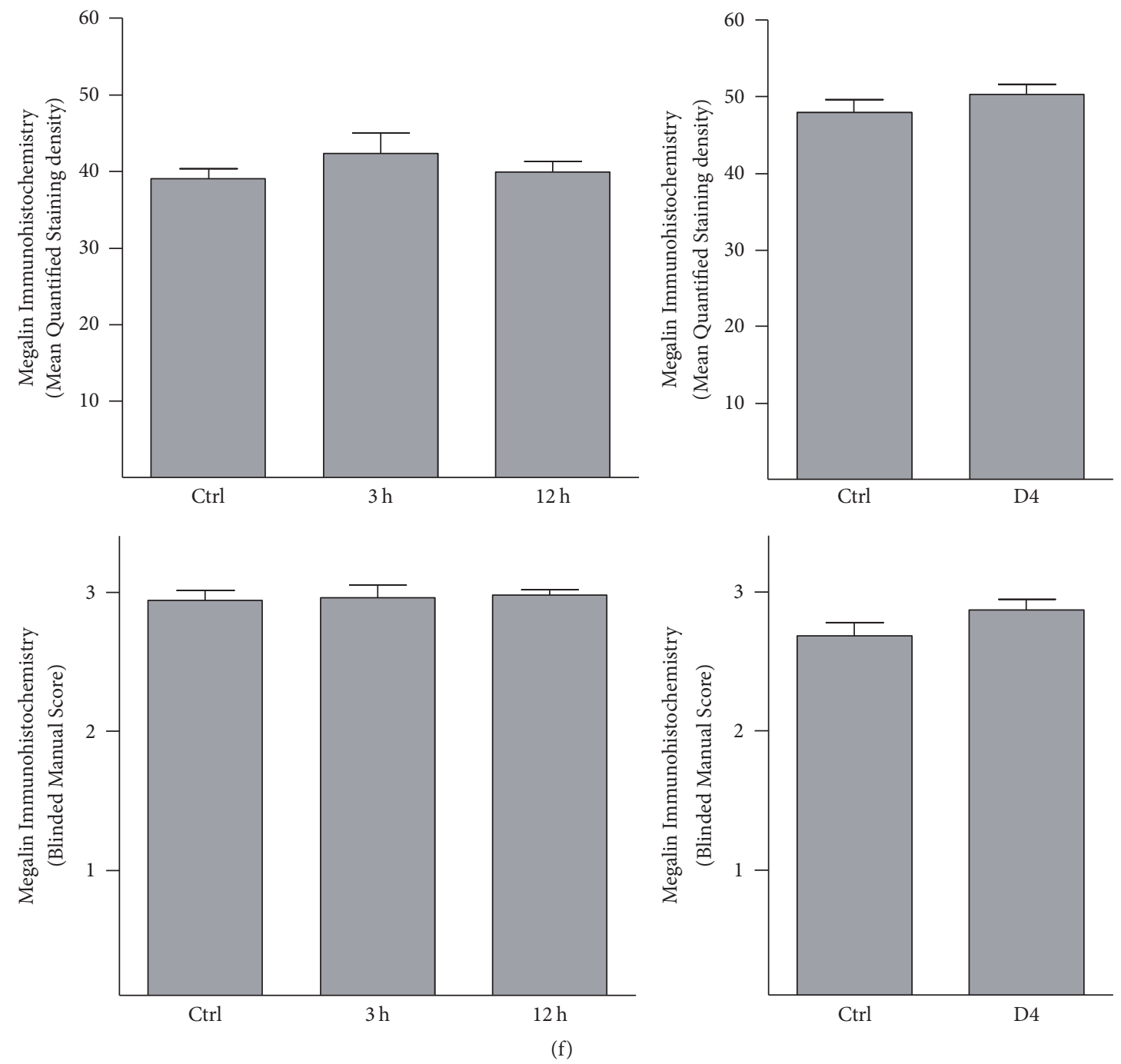

Figure 7: Continued. 


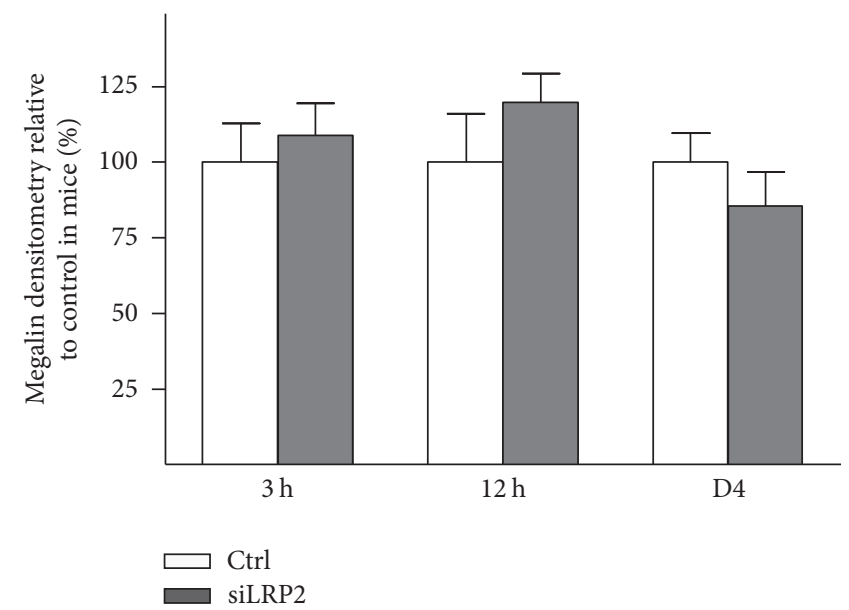

(g)

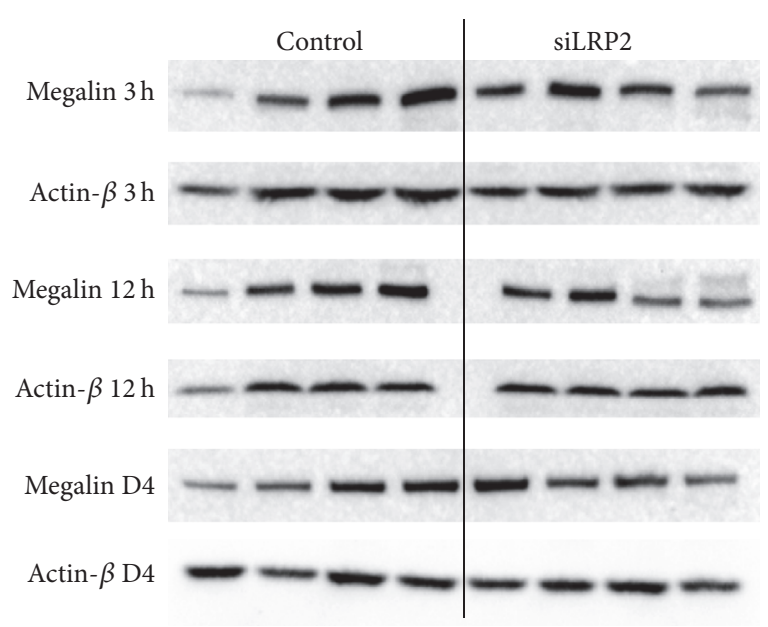

(h)

FIGURE 7: siLRP2 did not reduce renal megalin protein expression $3 \mathrm{~h}$ or $12 \mathrm{~h}$ after a single dose. (a) Immunohistochemistry (IHC) of a control mouse. (b) IHC $3 \mathrm{~h}$ after administration of siLRP2. (c) IHC $12 \mathrm{~h}$ after administration of siLRP2. (d) IHC of a control mouse after $3.5 \mathrm{days}$ of PBS vehicle. (e) IHC $3 \mathrm{~h}$ after a final seventh administration of siLRP2. (f) IHC staining density as quantified showed no significant difference; IHC staining density by visual scoring also revealed no significant difference. (g) Immunoblot densitometry of megalin in mice receiving siLRP2. (h) Immunoblots of megalin and actin for mice. $N=4$ per group for all analyses. Control mice for the $3 \mathrm{~h}$ and $12 \mathrm{~h}$ time points were the same and sacrificed $3 \mathrm{~h}$ after vehicle administration (all three groups were sacrificed the same day). For IHC, 10 images were scored for each mouse. All images 20x, measurement bar is $50 \mu \mathrm{m}$.

RNA) genes as a potential mechanistic explanation. One key difference is that the mRNA rebound effect occurred after 4-7 days of knockdown. In contrast, we identified rebound and upregulation as early as $12 \mathrm{~h}$ following administration.

Several limitations affect the generalizability of our results. Foremost amongst these limitations was the inability to reduce protein expression. As we discuss above, the membrane to cytoplasm ratio of the protein, modest mRNA knockdown effect, rapid rebound effect, and prolonged halflife all contributed to siRNA inefficacy. However, several unique features of megalin and LRP2 may additionally conspire to impair gene and protein knockdown. First, megalin has been shown to mediate uptake of siRNA in proximal tubule cells [34]. While this may appear counterintuitive to knock down the very protein responsible uptake, in this scenario, it is unlikely to have had a remarkable effect since (1) megalin's uptake capacity is high, and (2) protein expression reduction was never achieved. A second factor that may have affected efficacy is the rapid and repetitive recycling of the protein [25]. Megalin recycles from the cytoplasm to the cell membrane every 1.2 minutes. This factor should not have changed megalin's degradation half-life of $4.8 \mathrm{~h}$, but it might affect gene expression regulation. Megalin mRNA expression has been shown to be regulated by its compartmental protein expression [35]. Overexpression of both the membranebound megalin $\mathrm{COOH}$-terminal fragment (MCTF) and the soluble megalin intracellular domain (MICD) lead to significantly lower levels of megalin mRNA. Of note, the antibody used in our study maps to the carboxy-terminal of megalin. MCTF is cleaved by gamma-secretase into MICD and inhibition of gamma-secretase has been showed to restore megalin mRNA expression in MCTF overexpressed proximal tubular cells. Since blocking formation of MICD leads to increased megalin gene and protein expression, the opposite may hold true. Thus, if soluble intracellular megalin levels are decreased by siRNA, it follows that we might expect a significant counterregulatory increase in gene and protein expression.

Ultimately, we were not able to reach our goal of using siLRP2 as a therapeutic alternative to cilastatin or RAP. Both cilastatin and RAP have been used to block or decrease expression of megalin in the proximal tubule, preventing reabsorption of nephrotoxic compounds [21, 22]. Several alternative approaches can be considered in future experimentation. Nanocarrier molecules $[15,16]$ have been used to enhance renal delivery and efficacy of siRNA. These molecules have been used to prevent upregulation of expression in response to injury or disease but are not yet widely available. Their use holds potential to improve the degree of mRNA expression reduction. However, increased degree of knockdown does not overcome other factors like the extended protein half-life, rapid recycling to and from the membrane, rebound mRNA expression, and complex regulation of expression by the intracellular protein levels.

Approaches that might counterbalance the half-life and rebound expression include a continuous infusion of siRNA or more frequent dosing. The 12-hour time point for serial administration was chosen because of volume administration limitations, feasibility, and cost. The mRNA rebound phenomenon observed may have impaired the ability to achieve protein knockdown. While it is possible that a continuous infusion or more frequent dosing of siRNA would succeed in reducing megalin protein expression, cilastatin and RAP are better alternatives to focus on to reduce nephrotoxicity. 
Since both cilastatin and RAP can be administered once daily, siLRP2 is not an efficient or cost-effective means of preventing nephrotoxicity.

\section{Conclusions}

In conclusion, we demonstrated that $\operatorname{siLRP} 2$ administration was sufficient to modestly reduce renal mRNA expression in mice. This mRNA reduction did not lead to a reduction in megalin protein expression. A number of very strong publications have illustrated the use of siRNA to mitigate renal injury. Publication bias of positive results remains relevant in biomedical research. Although this investigation was encumbered by a number of limitations, we believe the data presented will assist other investigators in optimizing future RNAi experimentation with the kidney. The RNAi therapeutic approach may remain more suited to prevention of upregulation than reduction of baseline mRNA expression.

\section{Conflicts of Interest}

The authors have nothing to disclose.

\section{Acknowledgments}

Support for this work was provided by the Normon S. Coplon Satellite Award and NIH/NIDDK K08 DK107864 (Michael T. Eadon).

\section{References}

[1] M. S. Singh and D. Peer, "SiRNA delivery: current trends and future perspectives," Therapeutic Delivery, vol. 7, no. 2, pp. 5153, 2016.

[2] G. Stokman, Y. Qin, Z. Rácz, P. Hamar, and L. S. Price, "Application of siRNA in targeting protein expression in kidney disease," Advanced Drug Delivery Reviews, vol. 62, no. 14, pp. 1378-1389, 2010.

[3] C. Dutta, N. Avitahl-Curtis, N. Pursell et al., "Inhibition of glycolate oxidase with dicer-substrate siRNA reduces calcium oxalate deposition in a mouse model of primary hyperoxaluria type 1," Molecular Therapy, vol. 24, no. 4, pp. 770-778, 2016.

[4] A. Liebow, X. Li, T. Racie et al., "An investigational RNAi therapeutic targeting glycolate oxidase reduces oxalate production in models of primary hyperoxaluria," Journal of the American Society of Nephrology, vol. 28, no. 2, pp. 494-503, 2017.

[5] X. Zheng, G. Y. Zang, J. Jiang et al., "Attenuating ischemiareperfusion injury in kidney transplantation by perfusing donor organs with siRNA cocktail solution," Transplantation, vol. 100, no. 4, pp. 743-752, 2016.

[6] M. A. J. Moser, S. Arcand, H.-B. Lin et al., "Protection of the transplant kidney from preservation injury by inhibition of matrix metalloproteinases," PLOS ONE, vol. 11, no. 6, Article ID 0157508, 2016.

[7] P. R. Konkalmatt, L. D. Asico, Y. Zhang et al., "Renal rescue of dopamine D2 receptor function reverses renal injury and high blood pressure," JCI Insight, vol. 1, no. 8, 2016.

[8] M. F. Persson, W. J. Welch, C. S. Wilcox, and F. Palm, "Kidney function after in vivo gene silencing of uncoupling protein-2 in streptozotocin-induced diabetic rats," in Advances in Experimental Medicine and Biology, vol. 765, pp. 217-223, Springer, New York, NY, USA, 2013.

[9] B. A. Molitoris, P. C. Dagher, R. M. Sandoval et al., "siRNA targeted to 53 attenuates ischemic and cisplatin-induced acute kidney injury," Journal of the American Society of Nephrology, vol. 20, no. 8, pp. 1754-1764, 2009.

[10] X. Zhou, X. Zang, M. Ponnusamy et al., "Enhancer of zeste homolog 2 inhibition attenuates renal fibrosis by maintaining Smad7 and phosphatase and tensin homolog expression," Journal of the American Society of Nephrology, vol. 27, no. 7, pp. 20922108, 2016.

[11] Z. Li, L. Zhou, Y. Wang et al., "(Pro)renin receptor is an amplifier of wnt/beta-catenin signaling in kidney injury and fibrosis," Journal of the American Society of Nephrology, vol. 28, no. 8, pp. 2393-2408, 2017.

[12] H. Fu, Y. Tian, L. Zhou et al., "Tenascin-C is a major component of the fibrogenic niche in kidney fibrosis," Journal of the American Society of Nephrology, vol. 28, no. 3, pp. 785-801, 2017.

[13] X. Wei, Y. Xia, F. Li et al., "Kindlin-2 mediates activation of TGFbeta/Smad signaling and renal fibrosis," Journal of the American Society of Nephrology, vol. 24, no. 9, pp. 1387-1398, 2013.

[14] H. Shimizu, Y. Hori, S. Kaname et al., "SiRNA-based therapy ameliorates glomerulonephritis," Journal of the American Society of Nephrology, vol. 21, no. 4, pp. 622-633, 2010.

[15] S. Alidori, N. Akhavein, D. L. J. Thorek et al., "Targeted fibrillar nanocarbon RNAi treatment of acute kidney injury," Science Translational Medicine, vol. 8, no. 331, Article ID 331ra39, 2016.

[16] D. Chitkara, S. Singh, and A. Mittal, "Nanocarrier-based codelivery of small molecules and siRNA/miRNA for treatment of cancer," Therapeutic Delivery, vol. 7, no. 4, pp. 245-255, 2016.

[17] J. K. Edwards, "Nanomedicine: nanocarbon-mediated siRNA delivery to the kidney," Nature Reviews Nephrology, vol. 12, no. 6, p. 314, 2016.

[18] N. Shajari, B. Mansoori, S. Davudian, A. Mohammadi, and B. Baradaran, "Overcoming the challenges of siRNA delivery: nanoparticle strategies," Current Drug Delivery, vol. 14, no. 1, pp. 36-46, 2017.

[19] S. De, S. Kuwahara, and A. Saito, "The endocytic receptor megalin and its associated proteins in proximal tubule epithelial cells," Membranes, vol. 4, no. 3, pp. 333-335, 2014.

[20] R. Nielsen, E. I. Christensen, and H. Birn, "Megalin and cubilin in proximal tubule protein reabsorption: from experimental models to human disease," Kidney International, vol. 89, no. 1, pp. 58-67, 2016.

[21] Y. Hori, N. Aoki, S. Kuwahara et al., "Megalin blockade with cilastatin suppresses drug-induced nephrotoxicity," Journal of the American Society of Nephrology, vol. 28, no. 6, pp. 1783-1791, 2017.

[22] A. Onodera, M. Tani, T. Michigami et al., "Role of megalin and the soluble form of its ligand RAP in Cd-metallothionein endocytosis and Cd-metallothionein-induced nephrotoxicity in vivo," Toxicology Letters, vol. 212, no. 2, pp. 91-96, 2012.

[23] A. A. Akour, M. J. Kennedy, and P. M. Gerk, "The role of megalin in the transport of gentamicin across BeWo cells, an in vitro model of the human placenta," The American Association of Pharmaceutical Scientists Journal, vol. 17, no. 5, pp. 1193-1199, 2015.

[24] C. Schmitz, J. Hilpert, C. Jacobsen et al., "Megalin deficiency offers protection from renal aminoglycoside accumulation," The Journal of Biological Chemistry, vol. 277, no. 1, pp. 618-622, 2002. 
[25] A. E. Perez Bay, R. Schreiner, I. Benedicto et al., "The fastrecycling receptor megalin defines the apical recycling pathway of epithelial cells," Nature Communications, vol. 7, Article ID 11550, 2016.

[26] R. Kröning, D. Katz, A. K. Lichtenstein, and G. T. Nagami, "Differential effects of cisplatin in proximal and distal renal tubule epithelial cell lines," British Journal of Cancer, vol. 79, no. 2, pp. 293-299, 1999.

[27] J. D. Kaunitz, V. P. S. Cummins, D. Mishler, and G. T. Nagami, "Inhibition of gentamicin uptake into cultured mouse proximal tubule epithelial cells by L-lysine," The Journal of Clinical Pharmacology, vol. 33, no. 1, pp. 63-69, 1993.

[28] M. T. Eadon, B. K. Hack, C. Xu, B. Ko, F. Gary Toback, and P. N. Cunningham, "Endotoxemia alters tight junction gene and protein expression in the kidney," American Journal of PhysiologyRenal Physiology, vol. 303, no. 6, pp. F821-F830, 2012.

[29] M. T. Eadon, R. J. Hause, A. L. Stark et al., "Genetic variants contributing to colistin cytotoxicity: Identification of TGIF1 and HOXD10 using a population genomics approach," International Journal of Molecular Sciences, vol. 18, no. 3, article no. 661, 2017.

[30] C. A. Schneider, W. S. Rasband, and K. W. Eliceiri, "NIH Image to ImageJ: 25 years of image analysis," Nature Methods, vol. 9, no. 7, pp. 671-675, 2012.

[31] F. Czauderna, M. Fechtner, S. Dames et al., "Structural variations and stabilising modifications of synthetic siRNAs in mammalian cells," Nucleic Acids Research, vol. 31, no. 11, pp. 2705-2716, 2003.

[32] K. T. Love, K. P. Mahon, C. G. Levins et al., "Lipid-like materials for low-dose, in vivo gene silencing," Proceedings of the National Acadamy of Sciences of the United States of America, vol. 107, no. 5, pp. 1864-1869, 2010.

[33] J. Hong, Z. Qian, S. Shen et al., "High doses of siRNAs induce eri-1 and adar-1 gene expression and reduce the efficiency of RNA interference in the mouse," Biochemical Journal, vol. 390, no. 3, pp. 675-679, 2005.

[34] S. Gao, S. Hein, F. Dagnæs-Hansen et al., "Megalin-mediated specific uptake of chitosan/siRNA nanoparticles in mouse kidney proximal tubule epithelial cells enables AQP1 gene silencing," Theranostics, vol. 4, no. 10, pp. 1039-1051, 2014.

[35] Y. Li, R. Cong, and D. Biemesderfer, "The $\mathrm{COOH}$ terminus of megalin regulates gene expression in opossum kidney proximal tubule cells," American Journal of Physiology-Cell Physiology, vol. 295, no. 2, pp. C529-C537, 2008. 

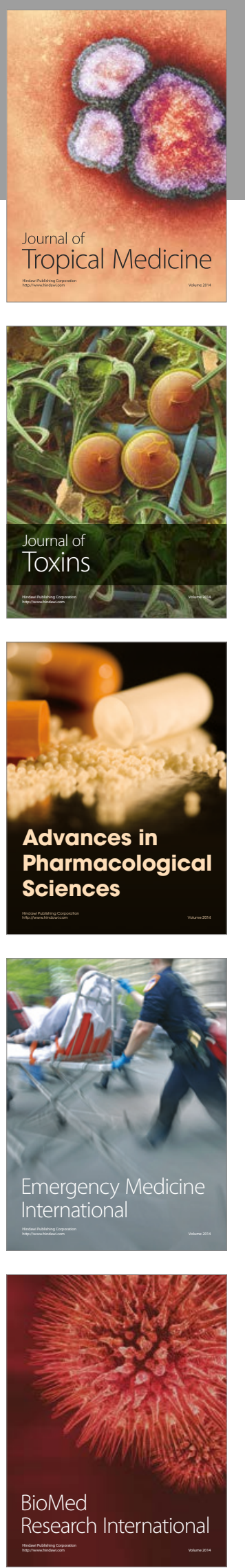
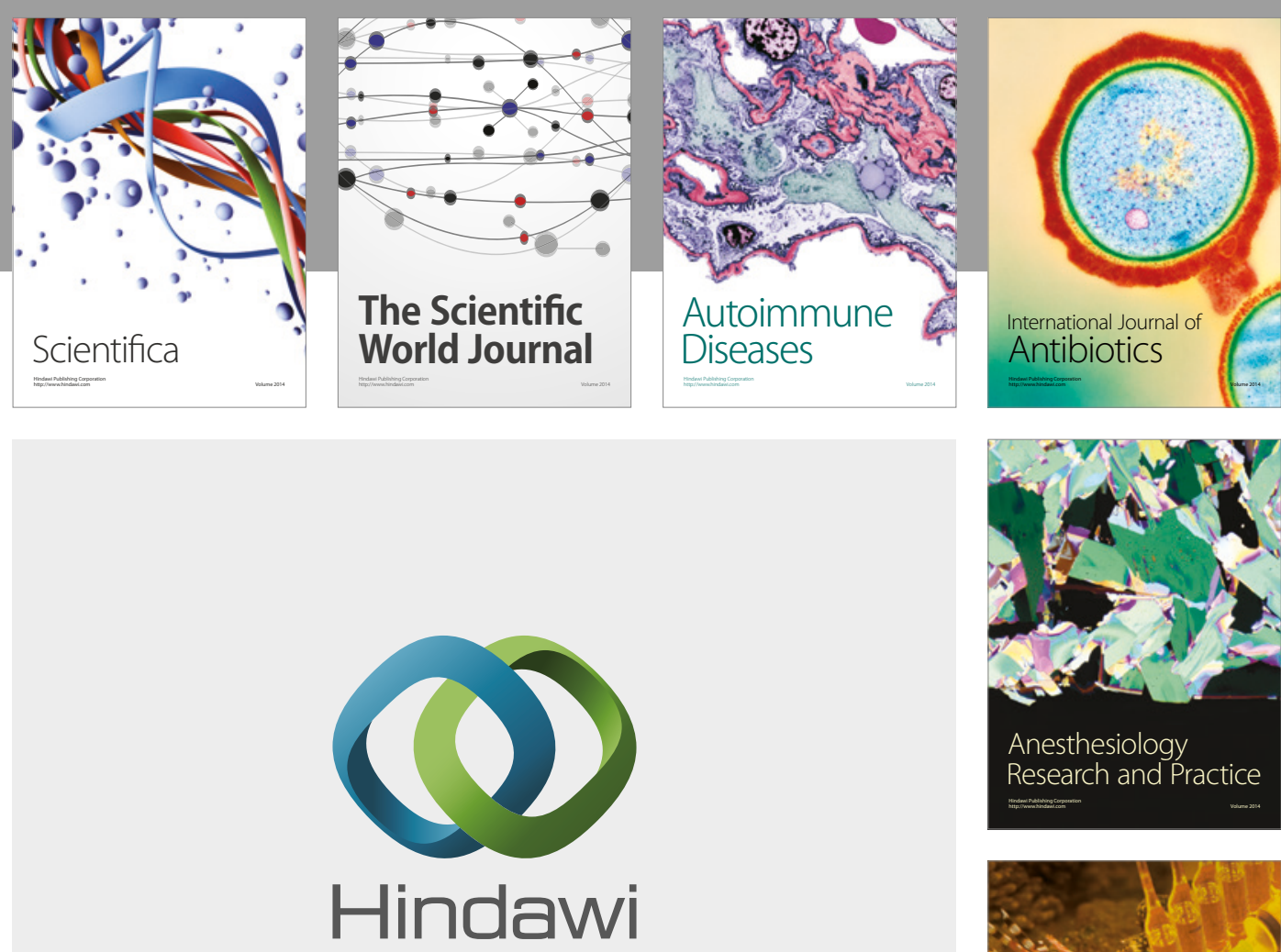

Submit your manuscripts at

https://www.hindawi.com
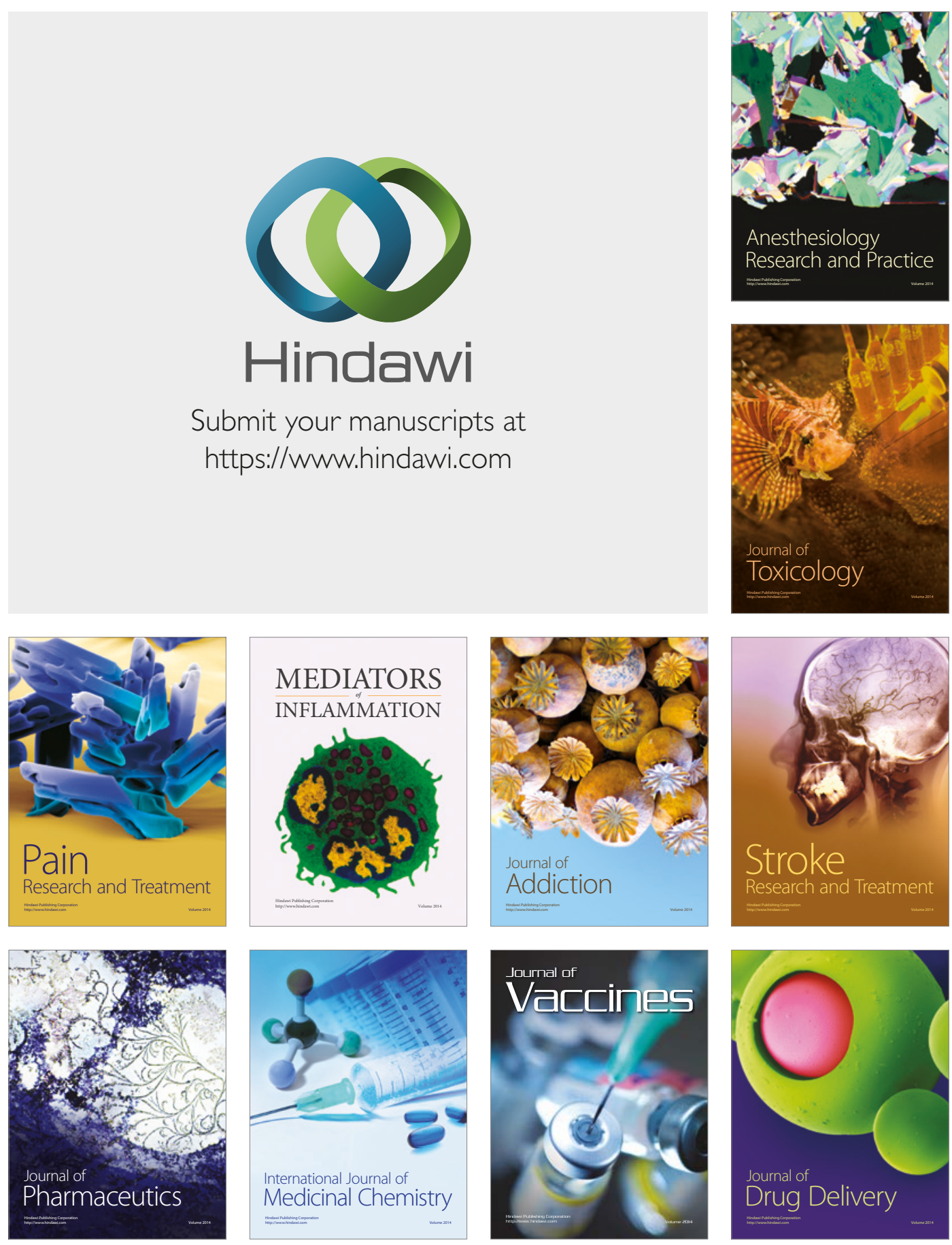